\title{
Crosstalk of BMP-4 and RA signaling pathways on Pomc gene regulation in corticotrophs
}

\author{
Leandro Nieto ${ }^{1, *}$, Mariana Fuertes ${ }^{1, *}$, Josefina Rosmino ${ }^{1,2}$, Sergio Senin ${ }^{1}$ and Eduardo Arzt ${ }^{1,3}$ \\ IInstituto de Investigación en Biomedicina de Buenos Aires (IBioBA) - CONICET - Partner Institute of the Max Planck Society, Buenos Aires, Argentina \\ 2División Endocrinología, Hospital General de Agudos 'Carlos G. Durand', Buenos Aires, Argentina \\ ${ }^{3}$ Departamento de Fisiología y Biología Molecular y Celular, Facultad de Ciencias Exactas y Naturales, Universidad de Buenos Aires, Buenos \\ Aires, Argentina
}

Correspondence should be addressed to E Arzt: earzt@ibioba-mpsp-conicet.gov.ar

*(L Nieto and M Fuertes contributed equally to this work)

\begin{abstract}
Retinoic acid (RA), an active metabolite of Vitamin A, and bone morphogenetic protein 4 (BMP-4) pathways control the transcription of pro-opiomelanocortin (Pomc), the precursor of ACTH. We describe a novel mechanism by which RA and BMP-4 act together in the context of pituitary corticotroph tumoral cells to regulate Pomc transcription. BMP-4 and RA exert a potentiated inhibition on Pomc gene expression. This potentiation of the inhibitory action on Pomc transcription was blocked by the inhibitory SMADs of the BMP-4 pathway (SMAD6 and SMAD7), a negative regulator of BMP-4 signaling (TOB1) and a blocker of RA pathway (COUP-TFI). AtT-20 corticotrophinoma cells express RA receptors (RARB, RXRA and RXRG) which associate with factors of BMP-4 (SMAD4 and SMAD1) signaling cascade in transcriptional complexes that block Pomc transcription. COUP-TFI and TOB1 disrupt these complexes. Deletions and mutations of the Pomc promoter and a specific DNA-binding assay show that the complexes bind to the RARE site in the Pomc promoter. The enhanced inhibitory interaction between RA and BMP-4 pathways occurs also in another relevant corticotroph gene promoter, the corticotropin-releasing hormone receptor $1(\mathrm{Crh}-\mathrm{r} 1)$. The understanding of the molecules that participate in the control of corticotroph gene expression contribute to define more precise targets for the treatment of corticotrophinomas.
\end{abstract}
Key Words
- BMP-4
- retinoic acid
- $\mathrm{POMC}$
- corticotroph
- Smad

Journal of Molecular Endocrinology (2019) 63, 161-174

\section{Introduction}

Retinoic acid (RA), the active acid metabolite of Vitamin $\mathrm{A}$, is a regulator of metabolic and cellular functions like cell differentiation, proliferation and apoptosis. RA acts mainly through a canonical pathway of gene expression regulation that involves the binding to nuclear RA receptors, which interact with specific regions in the DNA (Das et al. 2014) and are divided in two classes: $\mathrm{RA}$ receptors (RAR) and retinoid $\mathrm{X}$ receptors (RXRs). Three isoforms were described for RAR receptors, RARA,
RARB and RARG, while RXRA, RXRB and RXRG were described for RXR receptors (Maden 2007). Due to the ample variety of systemic processes in which RA participates, RA-modulating drugs have been used in certain clinical settings showing beneficial biological effects (Burnett et al. 2015, Abaza et al. 2017).

Cushing's disease originates in the excessive production of adrenocorticotropic hormone (ACTH) by a secreting pituitary corticotrophinoma and as a result 
of this over-production, the systemic level of circulating cortisol produced by the adrenal glands is dramatically increased (Dahia \& Grossman 1999, Melmed 2015, Albani et al. 2018). Corticotroph adenomas derive from normal pituitary corticotroph cells and represent about 4-8\% of the hormone-active tumors in the anterior pituitary (Dahia \& Grossman 1999). Cushing's disease is a very low-incidence disorder with the prevalence of active corticotroph tumors being about 40 cases per million, with higher prevalence in women (Pivonello et al. 2015). Transsphenoidal surgery is, in principle, the first approach for a treatment. This surgery procedure is not always successful, especially when the tumor is not completely resected, in which case, over time might expand, generating the necessity of other therapeutical options like chemotherapy, radiotherapy, repeated surgery or pharmacological treatment. In some cases, adrenalectomy is the decision of choice (Pivonello et al. 2015). Therapies aiming to reduce the circulating cortisol mainly act directly on the adrenal cortex by either blocking the synthesis of, or antagonizing peripheral glucocorticoid receptors, thus inhibiting glucocorticoid action or modulating ACTH pituitary hormone secretion (Pedroncelli 2010, Fleseriu \& Castinetti 2016, Fuertes et al. 2018, Grossman 2018, Langlois et al. 2018). Despite the ample variety of current available therapies (Fuertes et al. 2018), none has proven to be effective and to reliably provide a good, recurrencefree quality of life to the patient (Mooney et al. 2016, Bertagna 2018). The genetic and cellular mechanisms that underlie corticotrophinomas are poorly understood (Newell-Price et al. 2006), partially explaining the lack of effective treatments (Pivonello et al. 2015).

ACTH is derived from a 266 amino acid precursor polypeptide, pro-opiomelanocortin (Pomc) (Drouin 2016). The Pomc gene plays a central role among the hypothalamic-pituitary-adrenal axis regulatory mechanisms (Gagner \& Drouin 1985, Ray et al. 1995). The transcription activity of this gene is highly upregulated in ACTH-secreting pituitary adenomas (Arzt et al. 1992, Dahia \& Grossman 1999), thus suggesting Pomc transcriptional regulatory mechanisms as potential pharmacological targets. Recently, it was shown that proton-induced corticotropin-releasing hormone receptor 1 (Crh-r1) signaling regulates Pomc expression and ACTH production (Kameda et al. 2019).

Given its known role of inhibiting Pomc transcription, RA signaling is attractive as a target for long-term treatments. In this regard, RA treatment reduced ACTH secretion in the murine AtT-20 corticoptrophinomalike cell line and the proliferation rate of these cells
(Paez-Pereda et al. 2001). In vivo tumorigenesis studies using nude mice showed that RA treatment blocked the growth of corticotroph tumors compared to vehicletreated ones, reverting the characteristic signs of high corticosterone levels (Paez-Pereda et al. 2001). A 6-to-12month treatment scheme with RA in dogs with Cushing's disease not only normalized cortisol levels but prevented pituitary adenomas from recurring as well (Castillo et al. 2006). Two prospective clinical trials in human patients reported beneficial results in normalizing ACTH and cortisol levels after treatment with RA, for a period of 6-12 months (Pecori Giraldi et al. 2012, Vilar et al. 2016). The orphan nuclear receptor COUP-TFI negatively regulates retinoid action on target genes (Schuh \& Kimelman 1995, Bertacchi et al. 2019). Consistent with the presence of COUP-TFI in normal pituitary cells and not in tumoral ones, ACTH levels were unaltered after RA treatment in non-tumoral corticotrophs (Paez-Pereda et al. 2001).

Interestingly, RA treatment induces the expression of bone morphogenetic protein-4 (BMP-4), a cytokine of the TGFB superfamily involved in multiple tissue and organ maturation and differentiation processes, particularly during pituitary development (Sheng et al. 1997, Cushman \& Camper 2001, Davis et al. 2011). The mechanism mediating these actions involves the activation of specific signal transducers, the Smad proteins, which migrate to the nucleus to act as transcription factors (Shi $\&$ Massague 2003). Drugs acting at the epigenetic level have a permissive action for RA-induced expression of the $B M P$ gene in pituitary tumor cells (Yacqub-Usman et al. 2013). The expression of BMP-4 is reduced in Cushing's corticotrophinoma cells compared to corticotrophs from normal pituitary glands (Giacomini et al. 2006). Reduced expression of BMP-4 in corticotrophinomas is associated with epigenomic silencing, and the coincubation with the demethylating agent zebularine or the histone deacetylase inhibitor, trichostatin A, reversed the epigenetic changes and restored the expression of BMP-4 (Yacqub-Usman et al. 2012). BMP-4 treatment reduced ACTH secretion and proliferation of AtT-20 mouse corticotrophs, effects which were blocked in stably expressing SMAD4-DN or noggin AtT-20 clones (Giacomini et al. 2006). BMP-4 represses Pomc promoter activity involving SMAD1/4 and the interference with Pitx/Tpit activity (Nudi et al. 2005). Tob1, a transcription factor participating in bone formation processes by blocking BMP-4/SMAD1/7 signaling in osteoblasts (Yoshida et al. 2000), takes part in the molecular events that control the actions of BMP-4 .

To understand the regulatory mechanisms of Pomc expression by RA we analyzed in depth the signaling 
receptors involved in the interaction with BMP-4 signaling pathways and their joint action on the inhibition of Pomc transcription. The observed interaction of both pathways, at transcriptional level, resulted in a marked inhibition of the mechanism leading to production of ACTH, evidencing an interconnected regulatory network. Complexes between the RA receptors and SMAD signaling molecules that are negatively regulated by COUP-TFI and Tob1 contribute to the transcriptional control of Pomc and provide the molecular basis to understand the action of both BMP-4 and RA on the Pomc-ACTH expression in corticotrophs.

\section{Materials and methods}

Unless otherwise stated, reagents were obtained from Life Technologies/Thermo Fisher Scientific or SigmaAldrich/Merck.

\section{Cell culture}

AtT-20 pituitary corticotroph tumor cells were obtained from the American Type Culture Collection. AtT-20 cells were cultured in low-glucose DMEM (pH 7.3) supplemented with $10 \%$ fetal calf serum (FCS), $2.2 \mathrm{~g} / \mathrm{L}$ $\mathrm{NaHCO}_{3}, 10 \mathrm{mM}$ HEPES, and $2 \mathrm{mM}$ glutamine until they were confluent under $5 \% \mathrm{CO}_{2}$ atmosphere at $37^{\circ} \mathrm{C}$. Cells were treated with $100 \mathrm{ng} / \mathrm{mL}$ BMP-4 (R\&D Systems) or $100 \mathrm{nM}$ all-trans RA that was dissolved in ethanol-DMSO as a $10 \mathrm{mM}$ stock solution and handled in the dark. The diluting mixture was used in all the in vitro experiments as control.

\section{Plasmids}

The luciferase gene under the control of $770 \mathrm{bp}$ of the rat Pomc promoter includes all the necessary sequences for the expression and regulation of Pomc in pituitary cells in vivo (Liu et al. 1992). The following Pomc promoter reporter constructs that present deletions or mutations in the Pomc promoter useful for our studies (Fig. 3A) were kindly given by Jacques Drouin (Therrien \& Drouin 1991): JA289 (which contains a BMPRE deletion), JA361 (which contains a RARE deletion), JA316 (which contains a BMPRE point mutation) and JA327 (which contains a RARE point mutation). RARE-LUC reporter was kindly provided by Ethan Dmitrovsky (Petty et al. 2005).

BMPRE-LUC and mouse TOB1 expression vector were generously given by Yutaka Yoshida (Yoshida et al. 2000). SMAD6 and SMAD7 expression vectors were kindly given by Takeshi Imamura and Peter ten Dijke, respectively (Imamura et al. 1997, Nakao et al. 1997). COUP-TFI expression vector was kindly given by Ming-Jer Tsai (Pipaon et al. 1999). Crh-r1--LUC reporter vector is described elsewhere and was kindly given by Alon Chen (Kuperman et al. 2011).

\section{Transfection and reporter assays}

Cell transfection was performed with Lipofectamine and Plus Reagent according to manufacturer instructions and using standard procedures, as previously described (PaezPereda et al. 2001, Giacomini et al. 2006). After plating in 12 -well plates, cells were transfected for $6 \mathrm{~h}$ in OPTIMEM using $2 \mu \mathrm{L}$ of Lipofectamine, $1 \mu \mathrm{L}$ of Plus Reagent and $1 \mu \mathrm{g}$ total plasmid DNA per well. Cells were then washed and left to recover in DMEM overnight. The following day, cells were washed, left in serum-free DMEM for $6 \mathrm{~h}$ and treated for $24 \mathrm{~h}$ in serum-free DMEM with the indicated compounds. An additional $200 \mathrm{ng}$ of the RSV$\beta$-gal construct was co-transfected in all the experiments to correct for variations in transfection efficiency as previously described (Paez-Pereda et al. 2003). Luciferase activity was measured with a Junior luminometer (Berthold, Bad Wildbad, Germany). Results are shown as ratios of luciferase and/ $\beta$-galactosidase activity.

For transfections with SMAD6 and 7 expression vectors a dose-response curve was assayed from 0 to $500 \mathrm{ng}$ of each plasmid and a dose of $100 \mathrm{ng}$ was chosen for subsequent studies as this dose showed no alteration in basal activation levels.

A dose-response curve of TOB1 on Pomc transcription showed that from 100 to $300 \mathrm{ng}$, it stimulates the basal condition and most effectively blocks BMP-4 at $300 \mathrm{ng}$.

\section{Western blot analysis}

Western blot (WB) was performed as previously described (Paez-Pereda et al. 2003). Briefly AtT-20 cells were washed once with PBS ( $\mathrm{pH}$ 7.0), and then cell lysates were prepared in standard cracking buffer and boiled for $5 \mathrm{~min}$. Equal levels of protein $(30 \mu \mathrm{g})$ were electrophoresed by SDS-PAGE. Proteins were blotted onto nitrocellulose Western blotting membranes (Amersham) using standard procedures and anti-RXRA (sc-553, 1:1,000), anti-RXRB (sc-56869, 1:1,000), anti-RXRG (sc-555, 1:1,000), antiRARA (sc-551, 1:1,000), anti-RARB (sc-552, 1:1,000), anti-RARG (sc-7387, 1:1,000), anti-SMAD4 (sc-7966, 1:1,000), anti-SMAD1 (sc-7965, 1:1000) or anti-Actin (sc-47778, 1:5,000) (Santa Cruz Biotechnology Inc.) or 
anti-pSMAD1/5 (Ser463/465, 41D10) (Cell Signaling) were added. The primary antibodies were detected with HRP-conjugated anti-rabbit IgG secondary antibodies (Bio-Rad). Blots were imaged using the G:Box Chemi XT4 (Synoptics Ltd., Cambridge, United Kingdom) with SuperSignal West Dura kit according to manufacturer's instruction (Pierce Biotechnology).

\section{Immunoprecipitation (IP)}

Cells were seeded in P100 plates to full confluence in DMEM. Before performing the treatment, DMEM was changed to serum-free DMEM for $6 \mathrm{~h}$. Cells were treated in serum-free DMEM for $24 \mathrm{~h}$ with the indicated compound, washed with PBS, lysed on ice with modified RIPA buffer and immunoprecipitated with anti-SMAD4 or anti-SMAD1 using Protein G Agarose as described (Paez-Pereda et al. 2003). WB analyses were performed with the indicated antibodies. Mock control corresponds to the condition with all treatments present and immunoprecipitated with unspecific IgG of the same isotype of the antibody used to precipitate.

\section{Hormone measurements}

ACTH was determined by radioimmunoassay as previously described (Arzt et al. 1992).

\section{Preparation of nuclear extracts}

AtT-20 cells $\left(9 \times 10^{6}\right)$ were treated with RA, BMP-4 or vehicle for $24 \mathrm{~h}$, and then harvested in $1 \mathrm{~mL}$ cold PBS containing $0.6 \mathrm{mM}$ EDTA and pelleted at $5000 \boldsymbol{g}$ for $30 \mathrm{~s}$. Nuclear extracts were prepared as previously described (Giacomini et al. 2009). Cell pellets were gently resuspended in $350 \mu \mathrm{L}$ cold buffer A (10mM HEPES (pH 7.9), $10 \mathrm{mM}$ $\mathrm{KCl}, 0.1 \mathrm{mM}$ EDTA, 0.1 mM EGTA, $1 \mathrm{mM}$ dithiothreitol (DTT), $0.5 \mathrm{mM}$ phenylmethylsulfonyl fluoride, $1 \mu \mathrm{g} / \mathrm{mL}$ aprotinin and $1 \mu \mathrm{g} / \mathrm{mL}$ pepstatin) and allowed to swell on ice for $10 \mathrm{~min}$; then $5 \mathrm{~mL}$ of a $10 \%$ Igepal CA-630 solution was added to the cell suspensions, and cells were lysed on ice for $10 \mathrm{~min}$ and vortexed for $5 \mathrm{~s}$ every $2 \mathrm{~min}$. After centrifugation at $12,000 \boldsymbol{g}$ for $20 \mathrm{~min}$, the nuclear pellets were resuspended in $100 \mu \mathrm{L}$ cold buffer B $(20 \mathrm{mM}$ HEPES (pH 7.9), $600 \mathrm{mM} \mathrm{KCl,} 1 \mathrm{mM}$ EDTA, $1 \mathrm{mM}$ EGTA, $1 \mathrm{mM}$ DTT, $1 \mathrm{mM}$ phenylmethylsulfonyl fluoride and $25 \%$ glycerol), incubated for $40 \mathrm{~min}$ on ice and vortexed every $10 \mathrm{~min}$. After removal of nuclear debris by centrifugation at $16,000 \boldsymbol{g}$ for $10 \mathrm{~min}$ at $4^{\circ} \mathrm{C}$, the microextracts were stored at $-80^{\circ} \mathrm{C}$.

\section{EMSA}

EMSA was performed as previously described (Giacomini et al. 2009). Oligonucleotides were synthesized as single strand and the annealing of the complementary strands was allowed. Briefly, each oligonucleotide was dissolved to a final concentration of $1 \mathrm{mg} / \mathrm{mL}$ before use, the annealing reaction was performed in oligo annealing buffer (100mM Tris- $\mathrm{HCl}$ (pH 7.5), $1 \mathrm{M} \mathrm{NaCl}$ and $10 \mathrm{mM}$ EDTA) and equal volumes of both oligonucleotides were mixed and heated in a standard heat block at $95^{\circ} \mathrm{C}$. The following oligonucleotides were annealed: 5' -AGCGCTGCCAGGAAGGTCACGTCCAAGGCT-1' and 5'-AGCCTTGGACGTGACCTTCC TGGCAGCG-1'. Oligonucleotides $(1 \mu \mathrm{g})$ were labeled using [ $\alpha-32 \mathrm{P}]$-dCTP and large-fragment DNA polymerase I (Klenow fragment). For binding reactions, nuclear extracts were incubated for $30 \mathrm{~min}$ at room temperature in a total volume of $30 \mu \mathrm{L}$ containing $25 \mathrm{mM}$ HEPES ( $\mathrm{pH} 7.2$ ), $150 \mathrm{mM} \mathrm{KCl}, 10 \mathrm{mM}$ DTT, $10 \%$ glycerol, $40 \mathrm{mM}$ Spermidine and $500 \mu \mathrm{g} / \mathrm{mL}$ poly(deoxyinosinic-deoxycytidylic) used as nonspecific competitor DNA, with $50000 \mathrm{cpm}$ labeled probe. The samples were resolved on $6 \%$ polyacrylamide gels (acrylamide/bisacrylamide ratio of 29:1), buffered and ran for about $1.5 \mathrm{~h}$ in $0.5 \% \mathrm{TBE}$ at room temperature $(1 \times \mathrm{TBE}$ is $45 \mathrm{mM}$ Tris/borate/1 mM EDTA). Anti-Smad4 antibody, anti-RAR $\beta$ antibody, anti-RXR $\alpha$ antibody or anti-actin antibody (Santa Cruz Biotechnology Inc.) as control, were added to the nuclear extracts and incubated for $30 \mathrm{~min}$ at room temperature after addition of the probe. After incubation, the binding reaction mixture was applied to the gel as described above.

\section{Statistical analysis}

Statistical analyses were performed by ANOVA in combination with the Bonferroni post hoc test. Data are shown as mean \pm S.E.M.

\section{Results}

BMP-4 potentiates RA inhibitory effect on Pomc transcription

We first evaluated the interaction of RA and BMP-4 on ACTH secretion in AtT-20 cells and observed a potentiated inhibitory effect of RA in co-treatment with BMP-4 (Fig. 1A). We evaluated if this interaction occurs on the Pomc promoter and observed that single RA or BMP-4 treatments reduced luciferase expression in the Pomc reporter assay by approximately 50\%, with co-treatment 
leading to a slight but significant further reduction (Fig. 1B). The extend of potentiation of the inhibition when BMP-4 was combined with RA was $16-37 \%$ with respect to RA alone. The inhibitory effect of RA or BMP-4 and also the potentiation of this inhibition by the co-treatment was abolished in the presence of $100 \mathrm{ng}$ of the inhibitors of BMP-4 signaling, SMAD 6 or SMAD 7 (Fig. 1B). BMP-4 (3.9-folds) or RA (1.9-folds) treatment increased the phosphorylation of SMAD1/5 (which nicely mirrors its action show in Fig. 1B) which was not further altered by the co-treatment (four-folds) (Fig. 1C). Based on this, it looks possible that additional phosphorylation occurs with co-treatment.

To further study the crosstalk of BMP-4 and RA signaling pathways, we evaluated the effect of the co-treatment with specific reporters for both cascades. We observed an increase in transcriptional activation of RARE reporter after RA treatment, thus highlighting the importance of the DNA context of the RARE site (Buchler et al. 2003, Segal \& Widom 2009), which was potentiated by the co-treatment with BMP-4 (Fig. 1D). BMP-4 alone did not activate RARE transcription (Fig. 1D). In presence of SMAD 6 or SMAD 7, RA activated RARE transcription, but no activation enhancement was observed by the co-treatment with BMP-4 (Fig. 1D). BMP-4-specific SMAD-binding element reporter (BMPRE) showed activation by BMP-4, but no potentiated activation effect by the co-treatment with RA. RA alone did not activate BMPRE transcription (Fig. 1E). Consistent with cooperation between BMP and RA signaling in Pomc transcriptional inhibition, RA treatment failed to repress the Pomc reporter in AtT-20 cell clones that stably expressed a dominant negative SMAD4 protein (AtT-20 SMAD4-DN) (Fig. 1F).

\section{RA and BMP-4 signaling factors associate to form transcriptional complexes}

AtT-20 cells express the isoforms $\beta$ and $\gamma$ of the RA receptors (RAR) family, and the isoforms $\alpha, \beta$ and $\gamma$ of the RXR family (Fig. 2A). We studied by IP assays in cells treated with RA or BMP-4, whether any of these receptors associate with factors of the BMP-4 signaling pathway. Smad4, the common TGFB/BMP-SMAD signaling mediator, forms complexes with RARB, RXRA and RXRG (Fig. 2B). We studied the formation of complexes of RA receptors with SMAD1, a specific BMP-4 pathway signaling molecule, and observed interaction with RARB, RXRA and RXRG (Fig. 2C), the same isoforms as for SMAD4.

\section{Pomc promoter contains putative response elements for RA and BMP}

We analyzed the sequence of the promoter region of rat Pomc ( -483 to $+63 \mathrm{bp}$ ) with BLAST tool and INSECT 2.0 software (Rohr et al. 2013, Parra et al. 2016) and found two putative response elements, one for RA (RARE site), located between the -68 and $-63 \mathrm{bp}$ in the proximal segment of the Pomc promoter, and a BMP response element (BMPRE), located between -423 and $-419 \mathrm{bp}$ in the distal segment of the promoter (Fig. 3A). The relevance of those sites was validated functionally by the loss of response to RA and BMP respectively (Fig. 3B and C). With different reporter constructs containing deletions (Fig. 3B) or mutations (Fig. 3C) of the Pomc promoter, we observed that in the reporter containing only the RARE site (Fig. 3B, Pomc promoter with RARE site - BMPRE deletion) both the inhibition by RA and the potentiation of the co-treatment with BMP-4 are preserved. Similar results were obtained in the point mutation construct for BMPRE (Fig. 3C, Mutated BMPRE site). In the Pomc construct containing only the BMPRE site (Fig. 3B, Pomc promoter with BMPRE site - RARE deletion), we observed no inhibitory effect by RA treatment and no potentiation in co-treatment with BMP-4. This observation was corroborated in the point mutation construct for RARE (Fig. 3C, mutated RARE site).

In an EMSA assay using the RARE sequence as radiolabeled probe to assess the formation of protein complexes with this sequence, we observed the formation of complexes for AtT-20 cell nuclear extracts after BMP-4 or RA treatment or co-treatment. In the absence of RA, a binding is observed, which is in agreement with the constitutive complex observed with similar conditions in Fig. 2. The complex formed in the co-treatment condition was disrupted in the presence of anti-SMAD4 but not antiActin, showing that SMAD4 is part of the complex that binds to the RARE site. Moreover, when we evaluated RA treatment and RA/BMP-4 co-treated condition with antiRARB and anti-RXRA, the complexes formed were also displaced by the antibodies, revealing the presence of these RA receptors (Fig. 3D).

\section{COUP-TFI blocks RA-mediated transcriptional repression of Pomc}

COUP-TFI, a known negative regulator of RA signaling, disrupted the formation of the transcriptional complexes between RXRA, RXRG or RARB with SMAD4 in all the treatment conditions assayed (Fig. 4A). The interaction of RXRA or RARB with SMAD1 (Fig. 4B) was also disrupted, 
A

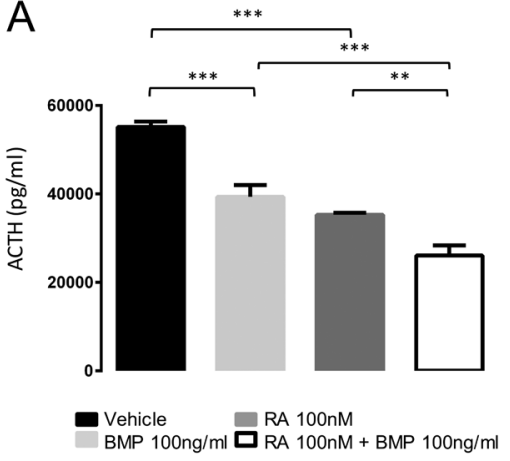

C

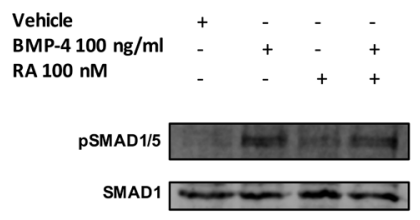

E

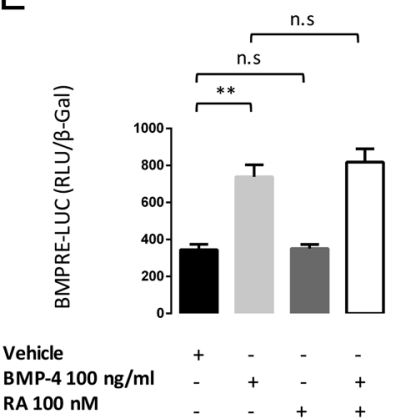

B
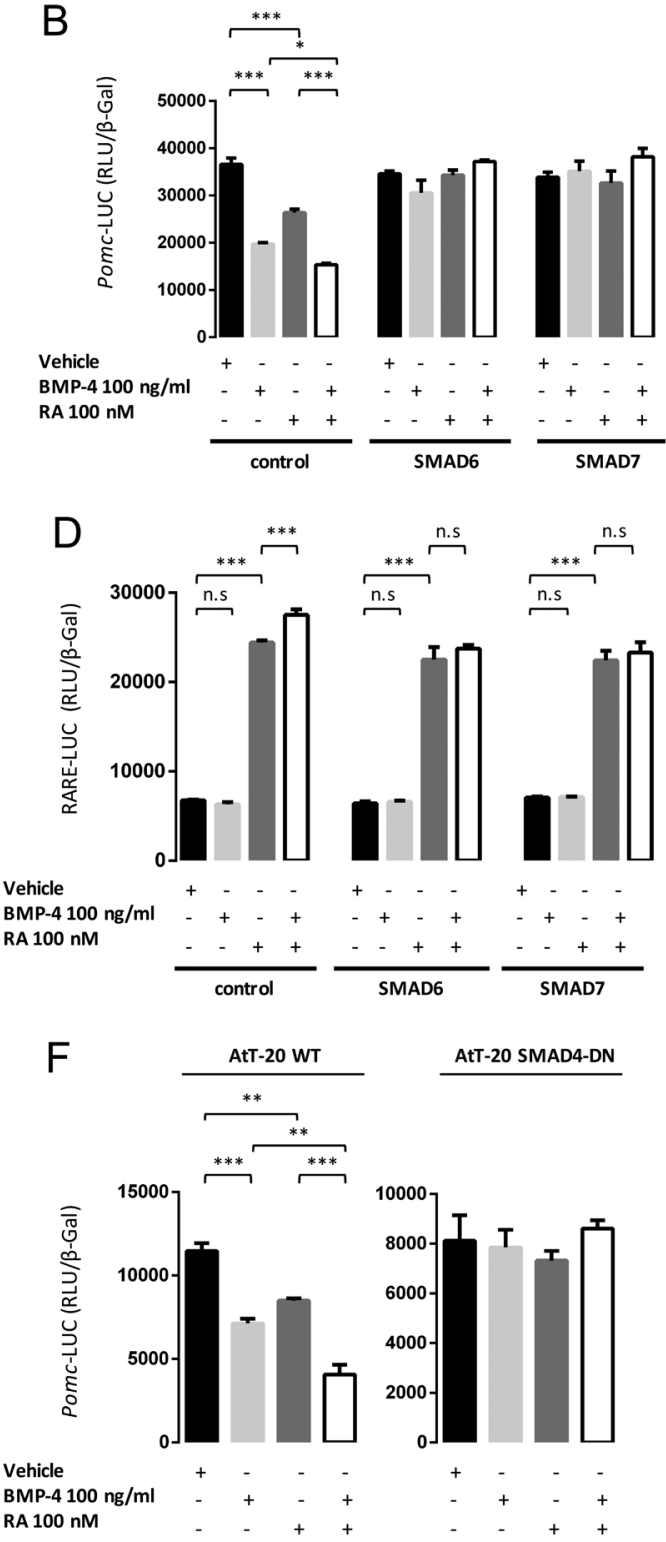

Figure 1

RA inhibitory action on ACTH secretion and Pomc transcription is increased by the BMP-4 signaling pathway. (A) AtT-20 cells were treated for $24 \mathrm{~h}$ with BMP-4, RA, or their combinations as indicated, under CRH $(100 \mathrm{nM})$ treatment. ACTH was measured in the supernatants by radioimmunoassay, and the average of three wells per treatment and S.E.M. from one representative experiment of three with similar results are shown. ${ }^{*} P<0.01 ; * \star * P<0.001$; ANOVA with Bonferroni contrast. (B) AtT-20 cells were co-transfected with Pomc-LUC reporter vector (500 ng), RSV- $\beta$-gal construct (200 ng) and SMAD6 or SMAD7 expression vector (100 ng) or empty vector and treated with BMP-4, RA or their combination as indicated. After 24-h treatment, luciferase activity was measured and normalized. Values indicating the mean \pm S.E.M. of luciferase to $\beta$-galactosidase ratio of one representative experiment of four with similar results are shown. $* P<0.05$; $* \star * P<0.001$; ANOVA with Bonferroni contrast. (C) PSMAD1/5 expression was studied by WB in AtT-20 cells treated with BMP-4, RA or their combination as indicated. (D) AtT-20 cells were co-transfected with RARE-LUC reporter vector (500 ng), RSV- $\beta$-gal construct (200 ng) and SMAD6 or SMAD7 expression vector (100 ng) or empty vector and treated with BMP-4, RA or their combination as indicated. After 24-h treatment, luciferase activity was measured and normalized. Values indicating the mean \pm S.E.M. of luciferase-to- $\beta$-galactosidase ratio of one representative experiment of four with similar results are shown. $* * * P<0.001 ;$ n.s, not significant; ANOVA with Bonferroni contrast. (E) AtT-20 cells were co-transfected with BMPRE-LUC reporter vector (500 ng) and RSV- $\beta$-gal construct (200 ng), and treated with BMP-4, RA or their combination as indicated. After 24 -h treatment, luciferase activity was measured and normalized. Values indicating the mean \pm s.E.M. of luciferase-to- $\beta$-galactosidase ratio of one representative experiment of three with similar results are shown. ${ }^{*} P<0.01$; n.s, not significant; ANOVA with Bonferroni contrast. (F) AtT-20 cells or AtT-20 SMAD4-DN stable clones were co-transfected with Pomc-LUC reporter vector ( $500 \mathrm{ng}$ ) and RSV- $\beta$-gal construct (200 ng) and treated with BMP-4, RA or their combination as indicated. After 24-h treatment, luciferase activity was measured and normalized. Values indicating the mean \pm S.E.M. of luciferase-to- $\beta$-galactosidase ratio of one representative experiment of three with similar results are shown. ${ }^{*} P<0.01 ; * \star \star * P<0.001$; ANOVA with Bonferroni contrast. 
while that for RXRG and SMAD1 was diminished only in the presence of BMP-4 and RA. The expression of COUPTFI blocked the effect of RA treatment in both the Pomc and RARE reporters, as well as the potentiation exerted by the co-treatment with BMP-4 and RA (Fig. 4C and D). As a control, we further analyzed the effect of COUP-TFI in the Pomc promoter constructs with deletion (Fig. 4E) or mutation (Fig. 4F) of the BMPRE site. Consistent with the previous results, as expected, the presence of COUP-TFI blocked the inhibition exerted by the treatment with RA and the potentiation with BMP-4 in both Pomc constructs.

\section{TOB1 specifically blocks BMP-4 inhibition on POMC transcription}

We next examined whether TOB1, a negative regulator of the BMP-4 pathway (Yoshida et al. 2000, Cao \& Chen 2005) affected the formation of the transcriptional complexes in AtT-20 cells. The expression of TOB1 hampered the formation of the complexes between RXRA, RXRG or RARB with SMAD4 (Fig. 5A). The same IP profile was obtained for the interaction between RXRA, RXRG or RARB with SMAD1 (Fig. 5B). TOB1 blocked the formation of these complexes though its effect was slightly less potent in comparison with SMAD4. The expression of TOB1 (300 ng) nullified the inhibitory action of BMP-4 treatment on Pomc and stimulated the basal condition, probably because it abolishes the action of the endogenous proteins (Fig. 5C).
The potentiated activation in transcription exerted by RA and BMP-4 co-treatment on RARE reporter was blocked by the presence of TOB1, which did not block the activation produced by RA treatment (Fig. 5D).

\section{RA and BMP-4 signaling interaction is also exhibited for Crh-r1 promoter}

We next analyzed the Crh-r1 promoter in order to examine if the mechanism of transcriptional regulation shown on the Pomc promoter by the crosstalk of RA and BMP-4 signaling pathways, takes place also in another corticotroph physiologically related regulation system. In accordance with the analysis of the Pomc promoter, in the sequence of the promoter region of mouse Crh$r 1(-2685$ to $+217 \mathrm{bp})$, we found with the INSECT 2.0 software (Rohr et al. 2013, Parra et al. 2016) one putative response element for RA (RARE site), in addition to four putative response elements for BMP (BMPRE site) (Fig. $6 \mathrm{~A})$. For this reporter, the transcriptional activation was also inhibited by the treatment of RA or BMP-4 (Fig. 6B). RA and BMP-4 co-treatment showed a potentiated inhibitory response. To assess the hypothesis of BMP-4 signaling pathway participation, the same functional experiment was performed in AtT-20 SMAD4-DN cells. In these cells, the effect of the treatment with RA or BMP-4 on Crh-r1 promoter was completely nullified (Fig. 6B).
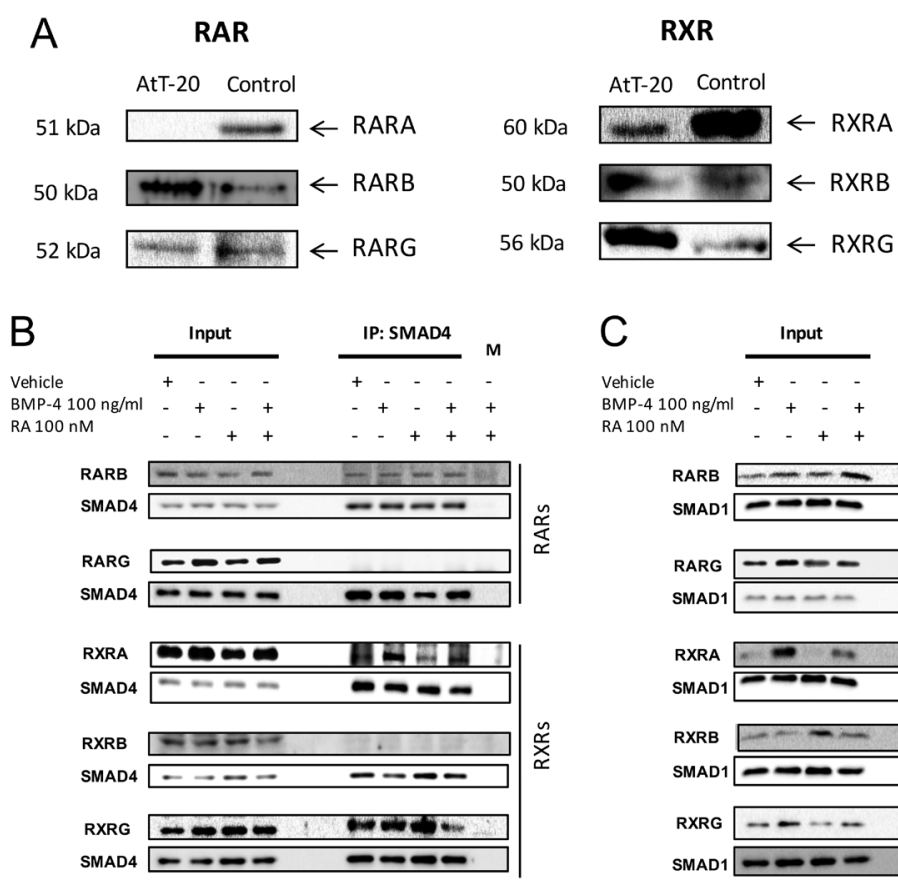

\section{Figure 2}

AtT-20 corticotroph cells express RA receptors, which interact with elements of the BMP-4 signaling pathway. (A) Retinoid and Rexinoid receptors (RAR and RXR) expression was studied by WB in AtT-20 cells and the specific band is indicated by an arrow. Cell extracts from HeLa (for RARA, RARG and RXRs) or HEK293T (for RARB) were used as positive controls. (B and C) AtT-20 cells were treated for $24 \mathrm{~h}$ with BMP-4, RA or their c combination as indicated. Cell lysates were IP with anti-SMAD4 (1 $\mu \mathrm{g})(\mathrm{B})$ or anti-SMAD1 (1 $\mu \mathrm{g})(\mathrm{C})$ and analyzed by WB. M, mock. One representative of three independent experiments with similar results is shown. 


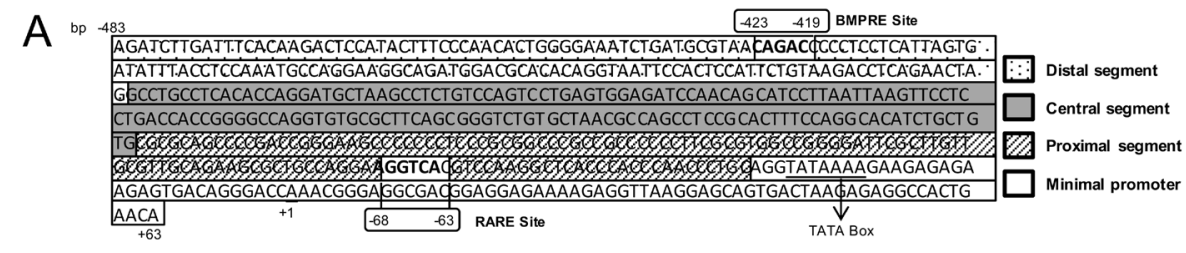

Reporter Constructions

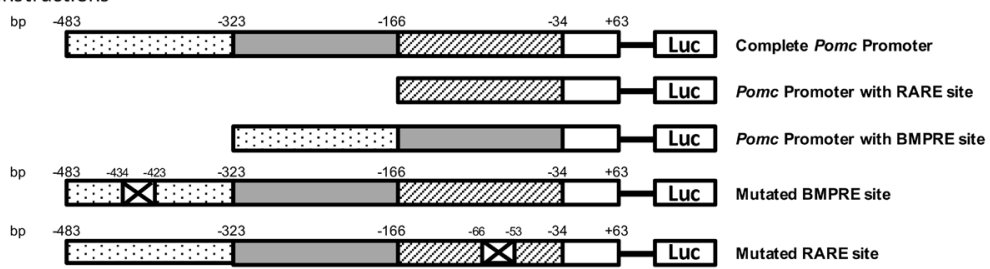

B

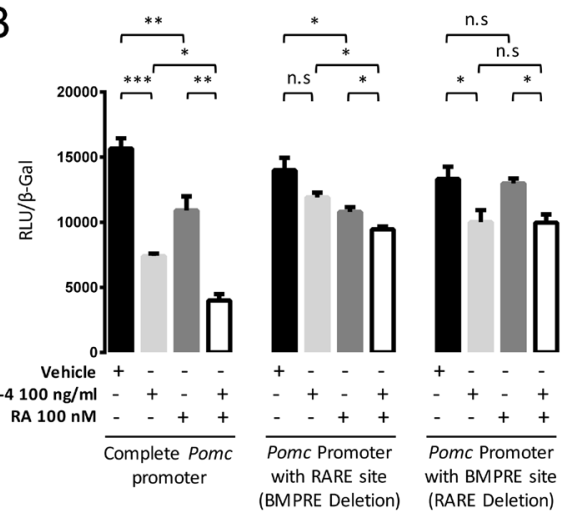

C
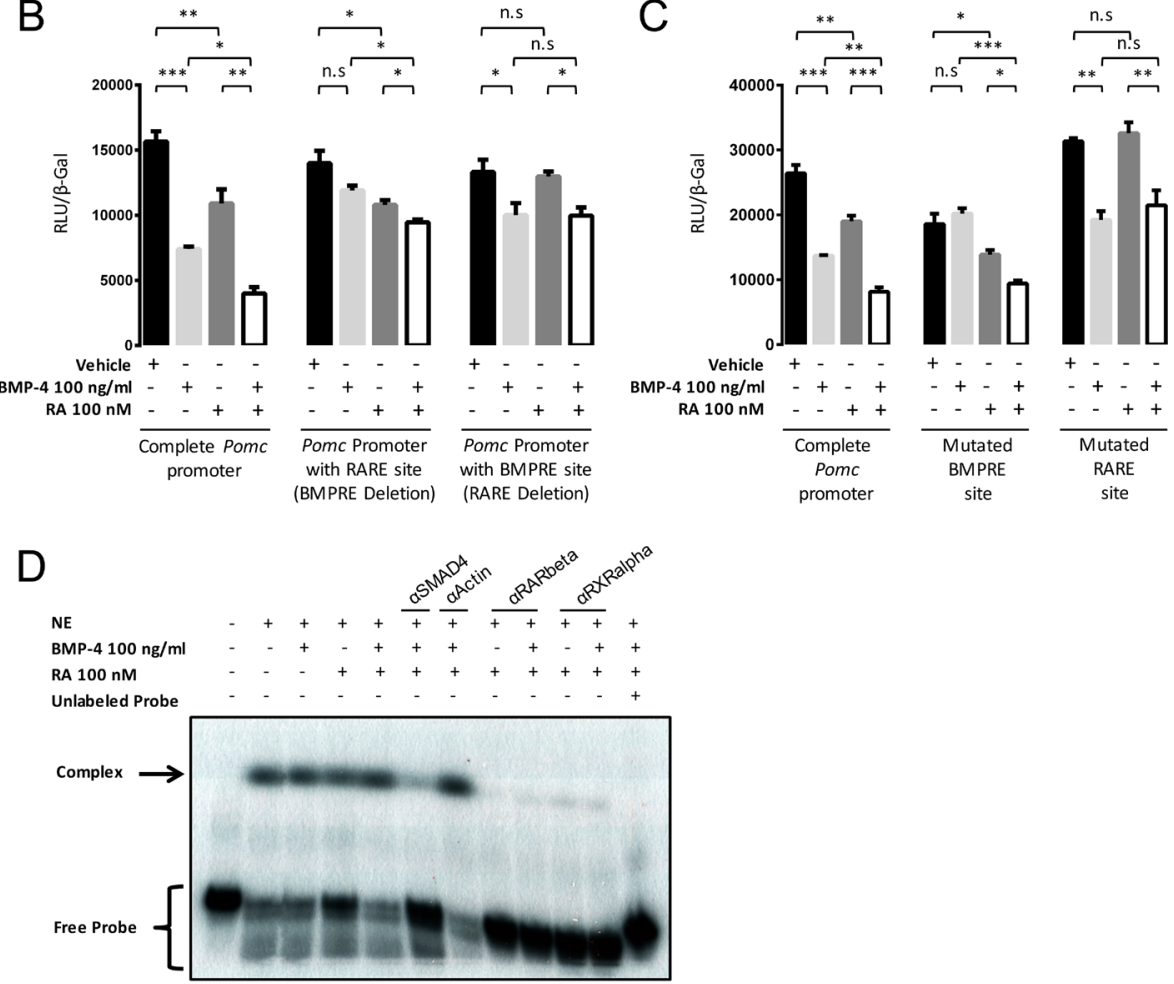

Figure 3

RARE and BMPRE sites at the Pomc promoter. (A) Schematic representation of rat Pomc promoter (GenBank: X03171.1) in which we found by in silico analysis two consensus sequence, one for RA (RARE site, -63 to -68 ) and one for BMP (BMPRE site, -419 to -423 ). The scheme shows the distal (dotted), central (gray), proximal (lined) and minimal (white) promoter regions, and the different Pomc constructs used (complete promoter, with RARE site or with BMPRE site only, and mutated BMPRE site or RARE site). (B and C) AtT-20 cells were co-transfected with Pomc-LUC constructs (500 ng) and RSV- $\beta$-gal vector (200 ng), and treated with BMP-4, RA or their combination as indicated. After 24-h treatment, luciferase activity was measured and normalized. Values indicating the mean \pm S.E.M. of luciferase-to- $\beta$-galactosidase ratio of one representative experiment of three with similar results are shown. $n$.S, not significant; $* P<0.05 ; * \star P<0.01 ; * \star \star P<0.001$; ANOVA with Bonferroni contrast. (D) EMSA of binding reactions using RARE sequence of the Pomc promoter as probe and AtT-20 cell nuclear extracts (NE) treated with BMP-4, RA or their combination as indicated. Binding complex is indicated by an arrow. Anti-SMAD4, anti-RARB and anti-RXRA antibodies $(2 \mu \mathrm{g})$ were used to disrupt the binding complex; anti-actin antibody was used as control. Unlabeled probe was used as competitor to displace the formed complex. The experiment shown is representative for two independent experiments with similar results.

\section{Discussion}

RA and BMP-4 have shown to be involved in the regulation of corticotrophinoma growth and hormone production, but their interrelation on Pomc transcription had not been analyzed until now. Our work describes a novel mechanism by which RA receptors of both the RAR and RXR families interact with SMADs, the signal 
A

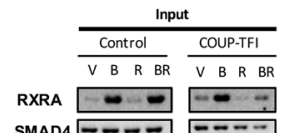
IP: SMAD4 SMAD4 $-\square-\square$

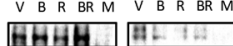

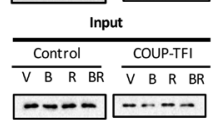

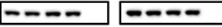

SMAD4

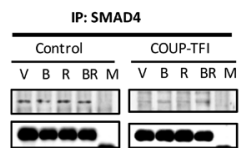

Input

Control COUP-TFI Control COUP-TFI RARB - CSMAD4

C
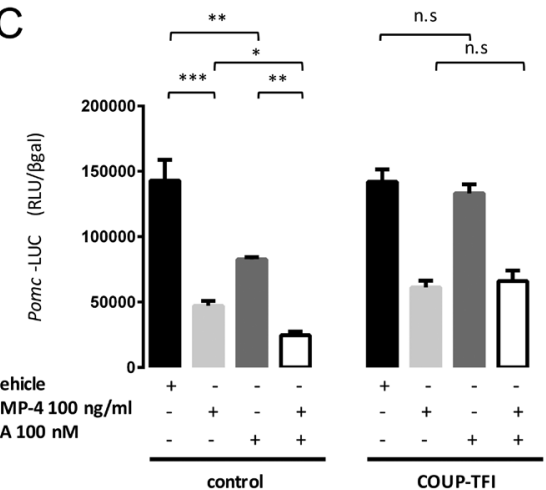

E
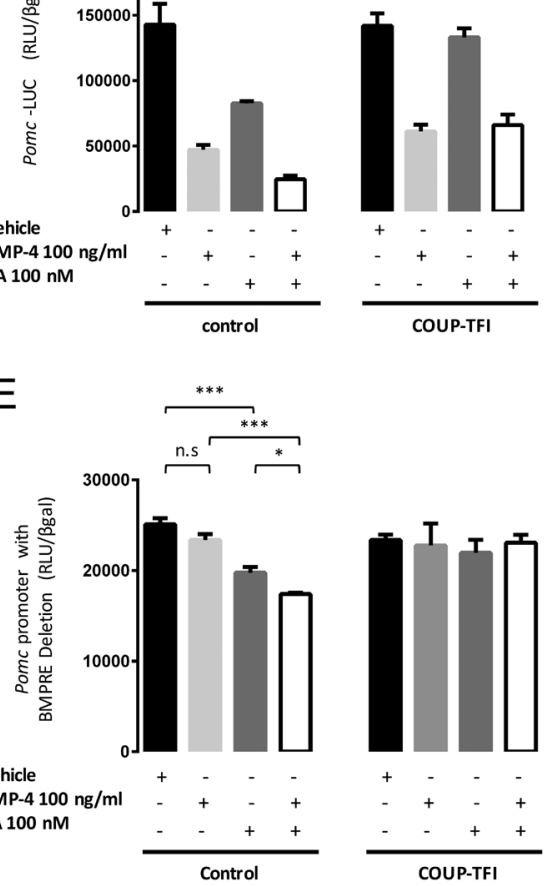

B
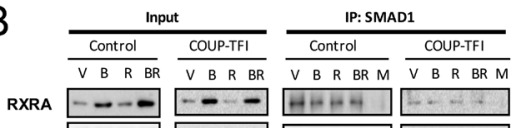
SMAD1

$+--\rightarrow$
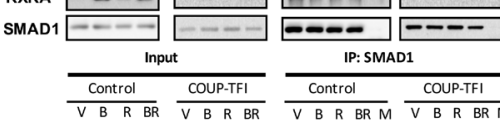
IP: SMAD1

RXRG

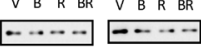
Control $\frac{\text { COUP-TFI }}{V B R B R M}$ SMAD1
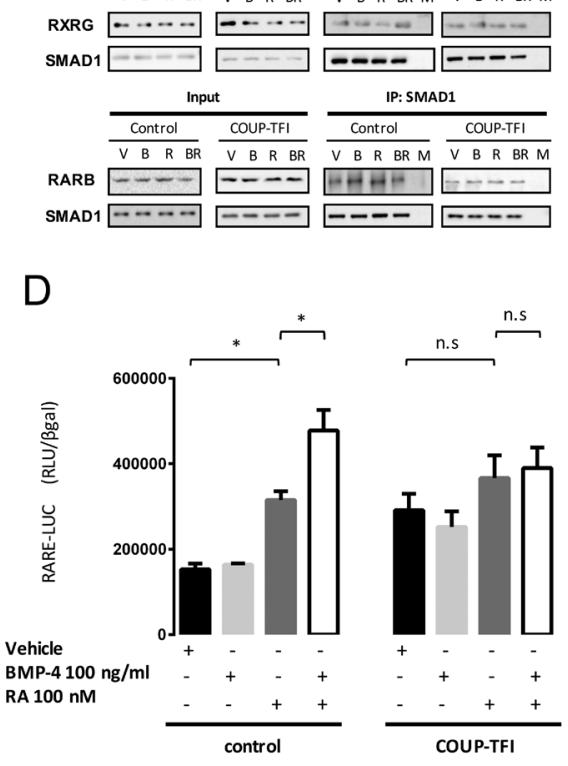

F

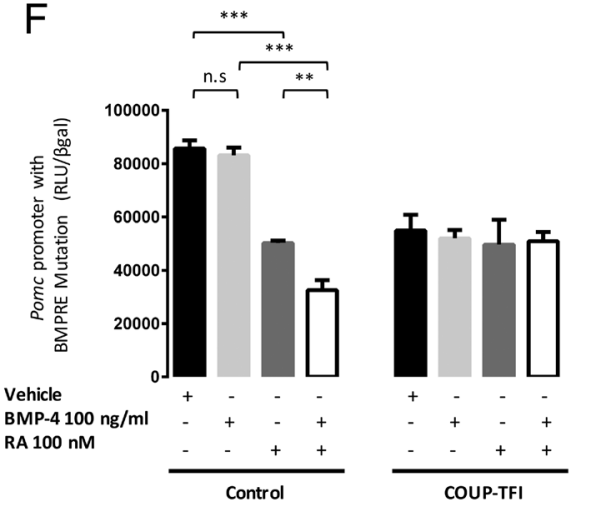

\section{Figure 4}

COUP-TFI hampers the formation of transcriptional complexes between elements of the BMP-4 signaling pathway and RA receptors. (A and B) AtT-20 cells were transfected with COUP-TFI expression vector or empty vector and treated for $24 \mathrm{~h}$ with BMP-4, RA or their combination as indicated. Cell lysates were IP with anti-SMAD4 $(1 \mu \mathrm{g})(\mathrm{A})$ or anti-SMAD1 $(1 \mu \mathrm{g})(\mathrm{B})$ and analyzed by WB. One representative of three independent experiments with similar results is shown. V, vehicle; $B, 100$ ng/mL BMP-4; R, 100 nM RA; BR, 100 ng/mL BMP-4 + 100 nM RA; M, mock. (C, D, E and F) AtT-20 cells were co-transfected with POMC-LUC (C) or RARE-LUC (D) or Pomc promoter with BMPRE deletion (E) or Pomc promoter with BMPRE mutation (F) reporter vector (500 ng), RSV- $\beta$-gal construct ( $200 \mathrm{ng}$ ) and COUP-TFI expression vector (400 ng) or empty vector and treated with BMP-4, RA or their combination as indicated. After 24 -h treatment, luciferase activity was measured and normalized. Values indicating the mean \pm S.E.M. of luciferase-to- $\beta$-galactosidase ratio of one representative experiment of three with similar results are shown. n.s, not significant; $* P<0.05 ; * \star P<0.01$; $* \star \star P<0.001 ;$ ANOVA with Bonferroni contrast.

transducers of the BMP-4 pathway. BMP-4 reduces the transcriptional activity of Pomc, enhancing the inhibitory effect of RA. RA receptors and SMAD proteins associate by forming transcriptional complexes that bind to the RARE consensus sequence in the Pomc promoter. Negative regulators of RA and BMP-4 pathways, COUP-TFI and
TOB1, disrupt the combined transcriptional complexes reversing the Pomc inhibition.

RA has an inhibitory effect on tumoral growth in AtT20 pituitary corticotroph cells (Paez-Pereda et al. 2001). The blockade of BMP-4 pathway by hampering Smad4 diminishes the inhibitory effect of RA on tumoral cell 
A

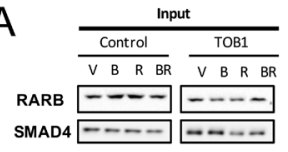

SMAD4

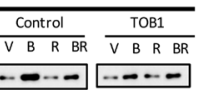
RXRA

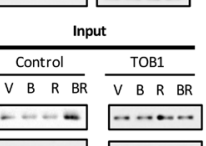
RXRG SMAD4 $-\cdots-\infty$

C

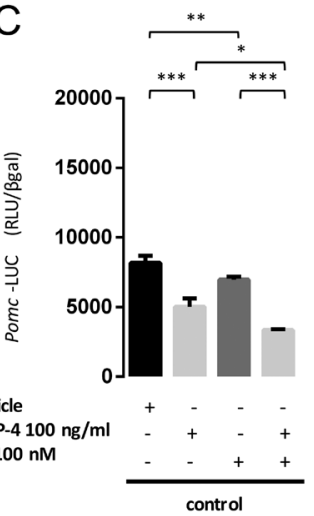

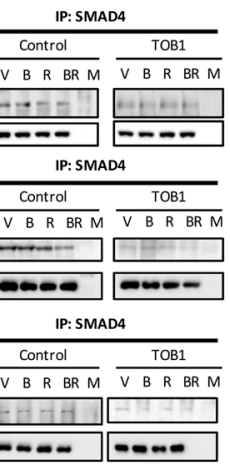

\section{B}

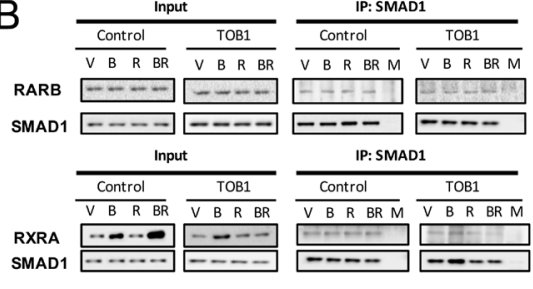

SMAD1
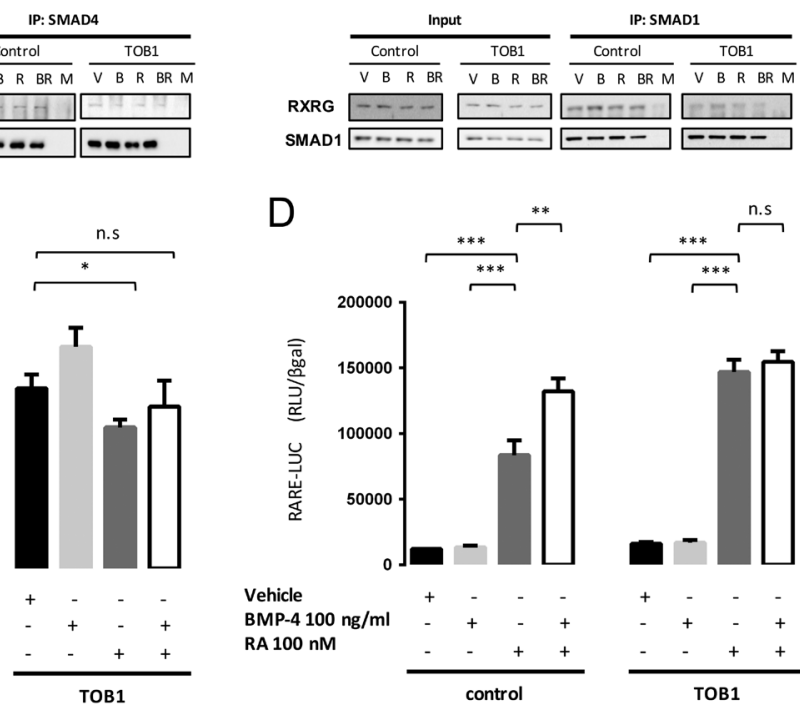

D

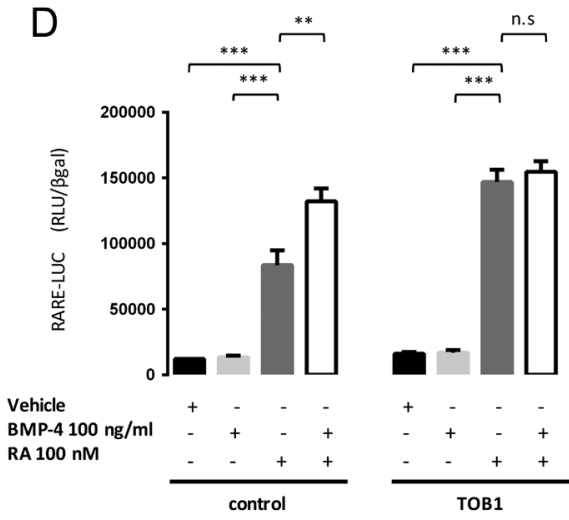

Figure 5

TOB1 disrupts the formation of transcriptional complexes between RA receptors and elements of the BMP-4 signaling. (A and B) AtT-20 cells were transfected with TOB1 expression vector or empty vector and treated for $24 \mathrm{~h}$ with BMP-4, RA or their combination as indicated. Cell lysates were IP with anti-SMAD4 (1 $\mu \mathrm{g})(\mathrm{A})$ or anti-SMAD1 $(1 \mu \mathrm{g})(\mathrm{B})$ and analyzed by WB. One representative of two independent experiments with similar results is shown. $\mathrm{V}$, vehicle; B, 100 ng/mL BMP-4; R, 100 nM RA; BR, 100 ng/ml BMP-4 + 100 nM RA; M, mock. (C and D) AtT-20 cells were co-transfected with Pomc-LUC (C) or RARE-LUC (D) reporter vector (500 ng), RSV- $\beta$-gal construct ( $200 \mathrm{ng}$ ) and TOB1 expression vector ( $300 \mathrm{ng}$ ) or empty vector, and treated with BMP-4, RA or their combination as indicated. After 24-h treatment, luciferase activity was measured and normalized. Values indicating the mean \pm s.E.M. of luciferase-to$\beta$-galactosidase ratio of one representative experiment of three with similar results are shown. n.s, not significant; $* P<0.05 ; * \star P<0.01 ; * \star \star x<0.001$; ANOVA with Bonferroni contrast.

proliferation and RA induces the expression of BMP-4 (Giacomini et al. 2006). It was also demonstrated that both RA and BMP-4 inhibit Pomc transcription and ACTH production (Paez-Pereda et al. 2001, Nudi et al. 2005). In this paper, we demonstrate for the first time the molecular mechanism involved in the interaction of both pathways in regulating Pomc expression in corticoptrophs.

The involvement of retinoic mediators in the BMP signaling has been also observed in mechanisms such as chondrogenesis. RA produced the inhibition of the phosphorylation of SMAD2 and SMAD3 and increased expression of SMAD7, explaining the RA-induced hypochondrogenesis of embryonic mesenchymal cells in vitro and showing a role of RA signaling in the mechanism of regulation of TGFB3/SMAD pathway (Yu \& Xing 2006). RAR $\gamma$ may function as coactivator of SMAD3 and SMAD4 for TGFB-transactivation pathways in a ligand-specific manner (Pendaries et al. 2003). RA is a known potent inhibitor of adipogenesis. The involvement of SMAD3 in the RA inhibition of pre-adypocites has been described (Marchildon et al. 2010).

The BMP-Smad pathway interaction with steroid receptors seems to be an important mechanism for its action. In lactotrophs, BMP-4 signaling exerts a stimulatory and pro-proliferative signal, in contrast to what is observed in corticotrophs (Giacomini et al. 2009). In these cells BMP-4 interacts with estrogens both for its proliferative action as well as for the regulation of the prolactin promoter (Paez-Pereda et al. 2003, Giacomini et al. 2009). BMP-4 also decreased folliclestimulating hormone (FSH) release in the sheep pituitary and amplified the suppression of FSH release and FSHB mRNA levels induced by $17 \beta$-estradiol in vitro (Faure et al. 2005). The crosstalk between SMADs and esteroids in cell proliferation in other systems has also been described (Matsuda et al. 2001, Kang et al. 2002). In corticotrophs the interaction seems to show no ligand dependency in so far as the complexes are formed in both cellular and 

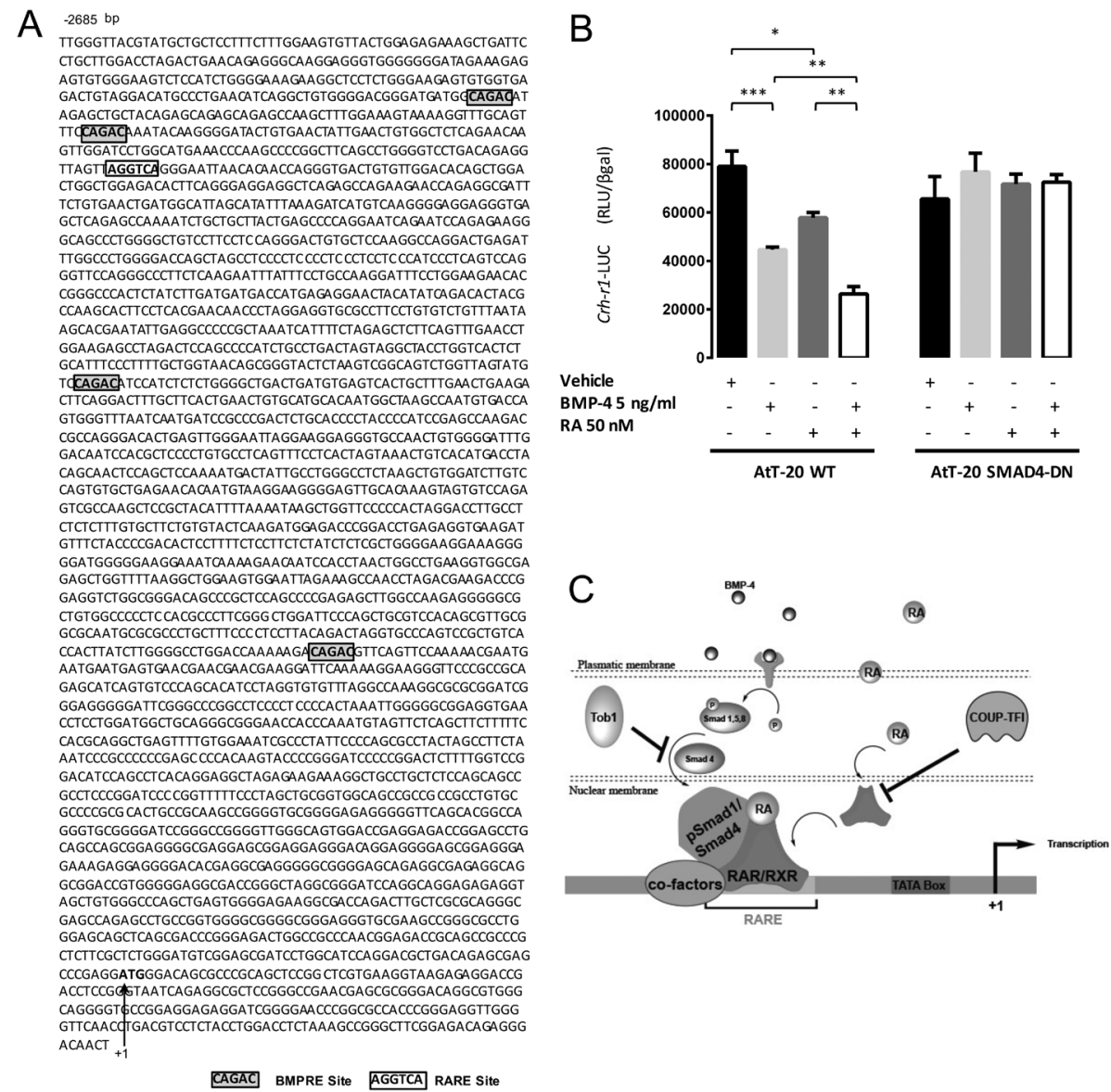

\section{Figure 6}

RA and BMP-4 signaling pathways interaction in pituitary corticotroph cells. (A) Schematic representation of mouse Crh-r1 promoter (GenBank: 12921). In silico analysis displays one consensus sequence for RA (RARE site, white box) and four for BMP (BMPRE site, gray boxes). (B) AtT-20 cells or AtT-20 SMAD4-DN stable clones were co-transfected with Crh-r1-LUC reporter vector (500 ng) and RSV- $\beta$-gal construct (200 ng) and treated with BMP-4, RA or their combination as indicated. After 24-h treatment, luciferase activity was measured and normalized. Values indicating the mean \pm s.E.M. of luciferase-to$\beta$-galactosidase ratio of one representative experiment of three with similar results are shown. $* P<0.05 ; * \star P<0.01$; $* \star \star * P<0.001$; ANOVA with Bonferroni contrast. (C) The proposed model of interaction between both RA and BMP-4 signaling pathways, in which the presence of the transcriptional complex formed by RA receptors and signal transducers SMADs on the RARE site triggers the inhibition of the transcriptional activity, while the presence of transcriptional modulators of both pathways, COUP-TFI for RA signaling and Tob1 for BMP-4 signaling, act to regulate and ameliorate the inhibitory effect of the interaction, and thus allowing Pomc transcription. Without ligands, these complexes have a constitutive binding probably without the cofactors induced by BMP-4 and RA that contribute to their potentiated action.

nuclear extracts (IP and gel shift experiments, respectively) under no stimulus. Many nuclear receptors can bind and, under certain conditions, activate transcription events on the basal level, even in the absence of ligands (Rosenfeld et al. 2006). As indicated by the SMAD6/7, SMAD4-DN and TOB1 experiments, as well as the phosphorylation of SMAD1/5, Smad factors are necessary for the action of RA. Cofactors of the SMAD-RA receptor complexes, which do not appear in the EMSA and coIP experiments, very likely are regulated by RA and BMP- 4 and contribute to their potentiated action.

During embryogenic development, BMP proteins play a key role controlling several steps toward the constitution of a functional pituitary gland. BMP-2 and BMP-4 have been shown to participate in the initial steps of the development of the anterior pituitary (Scully \& Rosenfeld 2002). BMP-4 is particularly critical during the developmental patterning of the pituitary, from the induction of Rathke's pouch to cell specificity commitment in anterior lobe. The regulation in the expression and range of action of the factors present in this network governing the process is complex and the proper balance in the activity of BMP signaling is crucial in pituitary organogenesis (Davis \& Camper 2007). Both BMP-4 and RA participate in multiple steps during pituitary development, controlling the circuitry of several signals 
aiming to enhance the differentiation and maturation processes, mediated by the induction of expression of several key transcription factors (Cushman \& Camper 2001, Suh et al. 2002). RA controls BMP-2 and BMP-4 regulation in embryonal carcinoma cells (Glozak \& Rogers 1996), and their combination favors smooth muscle cell differentiation by inducing apoptosis in neurons and glial cells (Glozak \& Rogers 1998, 2001). Intriguingly, as we show in this work, these pathways interact in the adult cell, in particular in the undifferentiated tumoral cells.

In order to verify if the RA-BMP-4 signaling complex is specific for the Pomc gene or could be acting on other target genes in the corticotroph, we investigated the Crh-r1 gene. This gene promoter also presents RARE and BMPRE motifs and when evaluated under RA or BMP-4 treatment showed similar inhibitory effects as well as a potentiated inhibition under the co-treatment. The sensitivities of these systems are presumably to be different as the Crh$r 1$ gene promoter showed a significantly lower inhibitory threshold of concentrations for both compounds to achieve a blockade in the transcriptional activation, in comparison to those required for Pomc inhibition. Other genes, under the control of RA and BMP-4 might be under the regulation of similar RA receptors/SMAD crosstalk mechanisms.

It has been observed that COUP-TFI expression in the normal pituitary is the reason why RA does not act on these cells (Paez-Pereda et al. 2001). In contrast, it has been shown that most of the human corticotrophinoma samples (29 out of 34) have negative expression for COUP-TFI (Bush et al. 2010). Therefore the clinical relevance of COUP-TFI could be a point to consider during the evaluation of a therapeutical approach. TOB1, a factor involved in osteoblast proliferation and bone formation processes, is a known BMP pathway inhibitor (Yoshida et al. 2000), and might have a potential role in the pituitary serving as a molecular tool to regulate BMP-4 action in corticotrophs. BMP-4 not only participates in the RA but also in the somatostatin analogs signaling on corticotrophinomas (Tsukamoto et al. 2010). Given the blocking action of TOB1 in the RA/BMP-4 interaction on Pomc transcription, its expression in tumoral corticotrophs could eventually hamper the clinical outcome of RA or other therapeutical scheme, underlying the significance of a proper biochemical characterization of the corticotrophinoma cases to be treated.

In conclusion, our study reveals a molecular mechanism in which the presence of co-regulatory elements of RA and BMP-4 signaling pathways interact to regulate Pomc transcriptional activity (Fig. 6C).
The expression of the molecules involved in these regulatory mechanisms will impact on the outcome of the response and may be relevant in order to define therapeutic targets for the treatment of corticotrophinomas.

\section{Declaration of interest}

The authors declare that there is no conflict of interest that could be perceived as prejudicing the impartiality of the research reported.

\section{Funding}

This work was supported by grants from the Max Planck Society, Germany; the University of Buenos Aires (grant number 20020170100230BA); CONICET (grant number D449 (01-03-2016)); the Agencia Nacional de Promoción Científica y Tecnológica (ANPCyT) (grant numbers PIDCLINICO-2014-0024 and PICT2016-1620), Argentina; and FOCEM-Mercosur (COF 03/11).

\section{Author contribution statement}

$L N, M F$, J R and S S performed the experiments. L N, M F and E A analyzed the data. E A designed research. L N, M F and E A wrote the manuscript. All authors approved the final manuscript.

\section{References}

Abaza Y, Kantarjian H, Garcia-Manero G, Estey E, Borthakur G, Jabbour E, Faderl S, O'brien S, Wierda W, Pierce S, et al. 2017 Longterm outcome of acute promyelocytic leukemia treated with alltrans-retinoic acid, arsenic trioxide, and gemtuzumab. Blood 129 1275-1283. (https://doi.org/10.1182/blood-2016-09-736686)

Albani A, Theodoropoulou M \& Reincke M 2018 Genetics of Cushing's disease. Clinical Endocrinology 88 3-12. (https://doi.org/10.1111/ cen.13457)

Arzt E, Stelzer G, Renner U, Lange M, Muller OA \& Stalla GK 1992 Interleukin-2 and interleukin-2 receptor expression in human corticotrophic adenoma and murine pituitary cell cultures. Journal of Clinical Investigation 90 1944-1951. (https://doi.org/10.1172/ JCI116072)

Bertacchi M, Parisot J \& Studer M 2019 The pleiotropic transcriptional regulator COUP-TFI plays multiple roles in neural development and disease. Brain Research 1705 75-94. (https://doi.org/10.1016/j. brainres.2018.04.024)

Bertagna X 2018 MANAGEMENT OF ENDOCRINE DISEASE: Can we cure Cushing's disease? A personal view. European Journal of Endocrinology 178 R183-R200. (https://doi.org/10.1530/EJE-18-0062)

Buchler NE, Gerland U \& Hwa T 2003 On schemes of combinatorial transcription logic. PNAS 100 5136-5141. (https://doi.org/10.1073/ pnas.0930314100)

Burnett AK, Russell NH, Hills RK, Bowen D, Kell J, Knapper S, Morgan YG, Lok J, Grech A, Jones G, et al. 2015 Arsenic trioxide and all-trans retinoic acid treatment for acute promyelocytic leukaemia in all risk groups (AML17): results of a randomised, controlled, phase 3 trial. Lancet: Oncology 16 1295-1305. (https://doi.org/10.1016/ S1470-2045(15)00193-X)

Bush ZM, Lopes MB, Hussaini IM, Jane Jr JA, Laws Jr ER \& Vance ML 2010 Immunohistochemistry of COUP-TFI: an adjuvant diagnostic tool for the identification of corticotroph microadenomas. Pituitary 13 1-7. (https://doi.org/10.1007/s11102-009-0189-8) 
Cao X \& Chen D 2005 The BMP signaling and in vivo bone formation. Gene 357 1-8. (https://doi.org/10.1016/j.gene.2005.06.017)

Castillo V, Giacomini D, Paez-Pereda M, Stalla J, Labeur M, Theodoropoulou M, Holsboer F, Grossman AB, Stalla GK \& Arzt E 2006 Retinoic acid as a novel medical therapy for Cushing's disease in dogs. Endocrinology 147 4438-4444. (https://doi.org/10.1210/ en.2006-0414)

Cushman LJ \& Camper SA 2001 Molecular basis of pituitary dysfunction in mouse and human. Mammalian Genome 12 485-494. (https://doi. org/10.1007/s003350040002)

Dahia PL \& Grossman AB 1999 The molecular pathogenesis of corticotroph tumors. Endocrine Reviews 20 136-155. (https://doi. org/10.1210/edrv.20.2.0358)

Das BC, Thapa P, Karki R, Das S, Mahapatra S, Liu TC, Torregroza I, Wallace DP, Kambhampati S, Van Veldhuizen P, et al. 2014 Retinoic acid signaling pathways in development and diseases. Bioorganic and Medicinal Chemistry 22 673-683. (https://doi.org/10.1016/j. bmc.2013.11.025)

Davis SW \& Camper SA 2007 Noggin regulates Bmp4 activity during pituitary induction. Developmental Biology 305 145-160. (https://doi. org/10.1016/j.ydbio.2007.02.001)

Davis SW, Mortensen AH \& Camper SA 2011 Birthdating studies reshape models for pituitary gland cell specification. Developmental Biology 352 215-227. (https://doi.org/10.1016/j.ydbio.2011.01.010)

Drouin J 201660 YEARS OF POMC: Transcriptional and epigenetic regulation of POMC gene expression. Journal of Molecular Endocrinology 56 T99-T112. (https://doi.org/10.1530/JME-15-0289)

Faure MO, Nicol L, Fabre S, Fontaine J, Mohoric N, Mcneilly A \& Taragnat C 2005 BMP-4 inhibits follicle-stimulating hormone secretion in ewe pituitary. Journal of Endocrinology 186 109-121. (https://doi.org/10.1677/joe.1.05988)

Fleseriu M \& Castinetti F 2016 Updates on the role of adrenal steroidogenesis inhibitors in Cushing's syndrome: a focus on novel therapies. Pituitary 19 643-653. (https://doi.org/10.1007/s11102-0160742-1)

Fuertes M, Tkatch J, Rosmino J, Nieto L, Guitelman MA \& Arzt E 2018 New insights in Cushing disease treatment With focus on a derivative of vitamin A. Frontiers in Endocrinology 9 262. (https://doi. org/10.3389/fendo.2018.00262)

Gagner JP \& Drouin J 1985 Opposite regulation of pro-opiomelanocortin gene transcription by glucocorticoids and CRH. Molecular and Cellular Endocrinology 40 25-32. (https://doi.org/10.1016/0303-7207(85)90154-6)

Giacomini D, Paez-Pereda M, Theodoropoulou M, Labeur M, Refojo D, Gerez J, Chervin A, Berner S, Losa M, Buchfelder M, et al. 2006 Bone morphogenetic protein- 4 inhibits corticotroph tumor cells: involvement in the retinoic acid inhibitory action. Endocrinology 147 247-256. (https://doi.org/10.1210/en.2005-0958)

Giacomini D, Paez-Pereda M, Stalla J, Stalla GK \& Arzt E 2009 Molecular interaction of BMP-4, TGF-beta, and estrogens in lactotrophs: impact on the PRL promoter. Molecular Endocrinology 23 1102-1114. (https:// doi.org/10.1210/me.2008-0425)

Glozak MA \& Rogers MB 1996 Specific induction of apoptosis in P19 embryonal carcinoma cells by retinoic acid and BMP2 or BMP4. Developmental Biology 179 458-470. (https://doi.org/10.1006/ dbio.1996.0275)

Glozak MA \& Rogers MB 1998 BMP4- and RA-induced apoptosis is mediated through the activation of retinoic acid receptor alpha and gamma in P19 embryonal carcinoma cells. Experimental Cell Research 242 165-173. (https://doi.org/10.1006/excr.1998.4075)

Glozak MA \& Rogers MB 2001 Retinoic acid- and bone morphogenetic protein 4-induced apoptosis in P19 embryonal carcinoma cells requires p27. Experimental Cell Research 268 128-138. (https://doi. org/10.1006/excr.2001.5281)

Grossman A 2018 Is the new treatment for Cushing's disease too sweet? Lancet: Diabetes and Endocrinology 6 2-3. (https://doi.org/10.1016/ S2213-8587(17)30341-8)
Imamura T, Takase M, Nishihara A, Oeda E, Hanai J, Kawabata M \& Miyazono K 1997 Smad6 inhibits signalling by the TGF-beta superfamily. Nature 389 622-626. (https://doi.org/10.1038/39355)

Kameda H, Yamamoto M, Tone Y, Tone M \& Melmed S 2019 Proton sensitivity of corticotropin-releasing hormone receptor 1 signaling to proopiomelanocortin in male mice. Endocrinology 160 276-291. (https://doi.org/10.1210/en.2018-00920)

Kang HY, Huang KE, Chang SY, Ma WL, Lin WJ \& Chang C 2002 Differential modulation of androgen receptor-mediated transactivation by Smad3 and tumor suppressor Smad4. Journal of Biological Chemistry 277 43749-43756. (https://doi.org/10.1074/jbc. M205603200)

Kuperman Y, Issler O, Vaughan J, Bilezikjian L, Vale W \& Chen A 2011 Expression and regulation of corticotropin-releasing factor receptor type 2 beta in developing and mature mouse skeletal muscle. Molecular Endocrinology 25 157-169. (https://doi.org/10.1210/ me.2010-0308)

Langlois F, Chu J \& Fleseriu M 2018 Pituitary-directed therapies for Cushing's disease. Frontiers in Endocrinology 9 164. (https://doi. org/10.3389/fendo.2018.00164)

Liu B, Hammer GD, Rubinstein M, Mortrud M \& Low MJ 1992 Identification of DNA elements cooperatively activating proopiomelanocortin gene expression in the pituitary glands of transgenic mice. Molecular and Cellular Biology 12 3978-3990. (https://doi.org/10.1128/mcb.12.9.3978)

Maden M 2007 Retinoic acid in the development, regeneration and maintenance of the nervous system. Nature Reviews: Neuroscience $\mathbf{8}$ 755-765. (https://doi.org/10.1038/nrn2212)

Marchildon F, St-Louis C, Akter R, Roodman V \& Wiper-Bergeron NL 2010 Transcription factor Smad3 is required for the inhibition of adipogenesis by retinoic acid. Journal of Biological Chemistry 285 13274-13284. (https://doi.org/10.1074/jbc.M109.054536)

Matsuda T, Yamamoto T, Muraguchi A \& Saatcioglu F 2001 Cross-talk between transforming growth factor-beta and estrogen receptor signaling through Smad3. Journal of Biological Chemistry 27642908 42914. (https://doi.org/10.1074/jbc.M105316200)

Melmed S 2015 Pituitary tumors. Endocrinology and Metabolism Clinics of North America 44 1-9. (https://doi.org/10.1016/j.ecl.2014.11.004)

Mooney MA, Simon ED \& Little AS 2016 Advancing treatment of pituitary adenomas through targeted molecular therapies: the Acromegaly and Cushing disease paradigms. Frontiers in Surgery 345 . (https://doi.org/10.3389/fsurg.2016.00045)

Nakao A, Afrakhte M, Moren A, Nakayama T, Christian JL, Heuchel R, Itoh S, Kawabata M, Heldin NE, Heldin CH, et al. 1997 Identification of Smad7, a TGFbeta-inducible antagonist of TGF-beta signalling. Nature 389 631-635. (https://doi.org/10.1038/39369)

Newell-Price J, Bertagna X, Grossman AB \& Nieman LK 2006 Cushing's syndrome. Lancet 367 1605-1617. (https://doi.org/10.1016/S01406736(06)68699-6)

Nudi M, Ouimette JF \& Drouin J 2005 Bone morphogenic protein (Smad)-mediated repression of proopiomelanocortin transcription by interference with Pitx/Tpit activity. Molecular Endocrinology 19 13291342. (https://doi.org/10.1210/me.2004-0425)

Paez-Pereda M, Kovalovsky D, Hopfner U, Theodoropoulou M, Pagotto U, Uhl E, Losa M, Stalla J, Grubler Y, Missale C, et al. 2001 Retinoic acid prevents experimental Cushing syndrome. Journal of Clinical Investigation 108 1123-1131. (https://doi.org/10.1172/ JCI11098)

Paez-Pereda M, Giacomini D, Refojo D, Nagashima AC, Hopfner U, Grubler Y, Chervin A, Goldberg V, Goya R, Hentges ST, et al. 2003 Involvement of bone morphogenetic protein 4 (BMP-4) in pituitary prolactinoma pathogenesis through a Smad/estrogen receptor crosstalk. PNAS 100 1034-1039. (https://doi.org/10.1073/ pnas.0237312100)

Parra RG, Rohr CO, Koile D, Perez-Castro C \& Yankilevich P 2016 INSECT 2.0: a web-server for genome-wide cis-regulatory modules https://jme.bioscientifica.com

https://doi.org/10.1530/JME-19-0059 (c) 2019 Society for Endocrinology Published by Bioscientifica Ltd. Printed in Great Britain 
prediction. Bioinformatics 32 1229-1231. (https://doi.org/10.1093/ bioinformatics/btv726)

Pecori Giraldi F, Ambrogio AG, Andrioli M, Sanguin F, Karamouzis I, Corsello SM, Scaroni C, Arvat E, Pontecorvi A \& Cavagnini F 2012 Potential role for retinoic acid in patients with Cushing's disease. Journal of Clinical Endocrinology and Metabolism 97 3577-3583. (https://doi.org/10.1210/jc.2012-2328)

Pedroncelli AM 2010 Medical treatment of Cushing's disease: somatostatin analogues and pasireotide. Neuroendocrinology 92120 124. (https://doi.org/10.1159/000314352)

Pendaries V, Verrecchia F, Michel S \& Mauviel A 2003 Retinoic acid receptors interfere with the TGF-beta/Smad signaling pathway in a ligand-specific manner. Oncogene 22 8212-8220. (https://doi. org/10.1038/sj.onc.1206913)

Petty WJ, Li N, Biddle A, Bounds R, Nitkin C, Ma Y, Dragnev KH, Freemantle SJ \& Dmitrovsky E 2005 A novel retinoic acid receptor beta isoform and retinoid resistance in lung carcinogenesis. Journal of the National Cancer Institute 97 1645-1651. (https://doi. org/10.1093/jnci/dji371)

Pipaon C, Tsai SY \& Tsai MJ 1999 COUP-TF upregulates NGFI-A gene expression through an $\mathrm{Sp1}$ binding site. Molecular and Cellular Biology 19 2734-2745. (https://doi.org/10.1128/mcb.19.4.2734)

Pivonello R, De Leo M, Cozzolino A \& Colao A 2015 The treatment of Cushing's disease. Endocrine Reviews 36 385-486. (https://doi. org/10.1210/er.2013-1048)

Ray DW, Gibson S, Crosby SR, Davies D, Davis JR \& White A 1995 Elevated levels of adrenocorticotropin (ACTH) precursors in postadrenalectomy Cushing's disease and their regulation by glucocorticoids. Journal of Clinical Endocrinology and Metabolism 80 2430-2436. (https://doi.org/10.1210/jcem.80.8.7629238)

Rohr CO, Parra RG, Yankilevich P \& Perez-Castro C 2013 INSECT: IN-Silico SEarch for Co-occurring Transcription factors. Bioinformatics 29 2852-2858. (https://doi.org/10.1093/ bioinformatics/btt506)

Rosenfeld MG, Lunyak VV \& Glass CK 2006 Sensors and signals: a coactivator/corepressor/epigenetic code for integrating signaldependent programs of transcriptional response. Genes and Development 20 1405-1428. (https://doi.org/10.1101/gad.1424806)

Schuh TJ \& Kimelman D 1995 COUP-TFI is a potential regulator of retinoic acid-modulated development in Xenopus embryos. Mechanisms of Development 51 39-49. (https://doi.org/10.1016/09254773(94)00346-O)

Scully KM \& Rosenfeld MG 2002 Pituitary development: regulatory codes in mammalian organogenesis. Science 295 2231-2235. (https:// doi.org/10.1126/science.1062736)
Segal E \& Widom J 2009 From DNA sequence to transcriptional behaviour: a quantitative approach. Nature Reviews: Genetics $10443-$ 456. (https://doi.org/10.1038/nrg2591)

Sheng HZ, Moriyama K, Yamashita T, Li H, Potter SS, Mahon KA \& Westphal H 1997 Multistep control of pituitary organogenesis. Science 278 1809-1812. (https://doi.org/10.1126/science.278.5344.1809)

Shi Y \& Massague J 2003 Mechanisms of TGF-beta signaling from cell membrane to the nucleus. Cell 113 685-700. (https://doi. org/10.1016/s0092-8674(03)00432-x)

Suh H, Gage PJ, Drouin J \& Camper SA 2002 Pitx2 is required at multiple stages of pituitary organogenesis: pituitary primordium formation and cell specification. Development 129 329-337.

Therrien M \& Drouin J 1991 Pituitary pro-opiomelanocortin gene expression requires synergistic interactions of several regulatory elements. Molecular and Cellular Biology 11 3492-3503. (https://doi. org/10.1128/mcb.11.7.3492)

Tsukamoto N, Otsuka F, Miyoshi T, Yamanaka R, Inagaki K, Yamashita M, Otani H, Takeda M, Suzuki J, Ogura T, et al. 2010 Effects of bone morphogenetic protein (BMP) on adrenocorticotropin production by pituitary corticotrope cells: involvement of up-regulation of BMP receptor signaling by somatostatin analogs. Endocrinology 151 1129-1141. (https://doi.org/10.1210/en.2009-1102)

Vilar L, Albuquerque JL, Lyra R, Trovão Diniz E, Rangel Filho F, Gadelha P, Thé AC, Ibiapina GR, Gomes BS, Santos V, et al. 2016 The role of isotretinoin therapy for Cushing's disease: results of a prospective study. International Journal of Endocrinology 2016 8173182. (https://doi.org/10.1155/2016/8173182)

Yacqub-Usman K, Duong CV, Clayton RN \& Farrell WE 2012 Epigenomic silencing of the BMP-4 gene in pituitary adenomas: a potential target for epidrug-induced re-expression. Endocrinology 153 3603-3612. (https://doi.org/10.1210/en.2012-1231)

Yacqub-Usman K, Duong CV, Clayton RN \& Farrell WE 2013 Preincubation of pituitary tumor cells with the epidrugs zebularine and trichostatin A are permissive for retinoic acid-augmented expression of the BMP-4 and D2R genes. Endocrinology 154 17111721. (https://doi.org/10.1210/en.2013-1061)

Yoshida Y, Tanaka S, Umemori H, Minowa O, Usui M, Ikematsu N, Hosoda E, Imamura T, Kuno J, Yamashita T, et al. 2000 Negative regulation of BMP/Smad signaling by Tob in osteoblasts. Cell 103 1085-1097. (https://doi.org/10.1016/s0092-8674(00)00211-7)

Yu Z \& Xing Y 2006 All-trans retinoic acid inhibited chondrogenesis of mouse embryonic palate mesenchymal cells by down-regulation of TGF-beta/Smad signaling. Biochemical and Biophysical Research Communications 340 929-934. (https://doi.org/10.1016/j. bbrc.2005.12.100)

Received in final form 1 August 2019

Accepted 6 August 2019

Accepted Preprint published online 6 August 2019 (c) 2019 Society for Endocrinology Published by Bioscientifica Ltd. Printed in Great Britain 